\title{
Retrospective Review
}

\section{What is the Correlation Between Facet Joint Radiofrequency Outcome and Response to Comparative Medial Branch Blocks?}

\author{
Sara Christensen Holz, MD, and Nalini Sehgal, MD
}

From: University of Wisconsin School of Medicine and Public Health, Madison, WI

Dr Sehgal is Professor, Pain Medicine Fellowship Program Director, Department of Orthopedics \& Rehabilitation, University of Wisconsin School of Medicine and Public Health, Madison, WI

Address Correspondence: Sara Christensen Holz, MD Assistant Professor University of Wisconsin School of Medicine and Public Health Madison, WI E-mail:

ChristensenHolz@rehab.wisc. edu

Disclaimer: There was no external funding in the preparation of this manuscript. Conflict of interest: Each author certifies that he or she, or a member of his or her immediate

family, has no commercial association (i.e., consultancies, stock ownership, equity interest, patent/licensing arrangements, etc.) that might pose a conflict of interest in connection with the submitted manuscript.

Manuscript received: 01-27-2015 Revised manuscript received: 05-12-2015, 09-09-2015 Accepted for publication: 10-13-2015

Free full manuscript: www.painphysicianjournal.com
Background: Facet joint pain is a common cause of low back pain. There are no physical exam findings that provide a reliable diagnosis. Diagnosis is made by medial branch block injections $(\mathrm{MBB})$. Once the source of pain has been determined, radiofrequency neurotomy (RFN) can be performed. Previous studies have shown that RFN reduces level of pain and improves function. No study has tried to correlate MBB results with outcomes after RFN.

Objectives: (1) Estimate percentage decrease in pain, decrease in analgesic use, and increase in activity tolerance after facet joint radiofrequency neurotomy (2) Determine correlation between percentage pain relief or duration of pain relief after MBB and RFN outcomes.

Study Design: Retrospective review of patients undergoing RFN, who had $\geq 70 \%$ pain relief on 2 sets of MBB with $0.5-1 \mathrm{~mL}$ of $2 \%$ lidocaine (MBB 1) and $0.75 \%$ bupivacaine (MBB 2). IRB approval was obtained before data collection began.

Setting: All patients undergoing RFN between 12/06-1/10 at University Spine and Pain clinics.

Methods: Subgroup analysis was performed based on response to MBB, a) $100 \%$ pain relief and $<100 \%$ pain relief after MBB 1 and 2 and a) those with $>8$ hours and $\leq 8$ hours pain relief after MBB 1 and 2. Correlational analysis was conducted to determine the correlation between a) percent pain relief after MBB1 and 2 and percent change in pain after RFN and b) duration of pain relief after MBB 1 and 2 and percent change in pain relief after RFN. Outcome measures: Pain intensity, disability index, analgesic use, and patient perception of benefit.

Results: Mean improvement of Disability scores at 3 months was $12.63(P=0.001)$, percent pain relief was $47.68 \%(P=0.001)$. Patients with $100 \%$ pain relief after MBB 1 had greater improvement of disability scores $(P=0.008)$. Those with $>8$ hours pain relief after MBB 1 had greater reduction in pain $(P=0.014)$. Pearson correlation analysis showed no correlation between percent pain relief or duration of pain relief after MBB and percent pain relief after RFN.

Limitations: This was a small observational study with short-term follow up.

Conclusion: Patients had improved disability scores and decreased pain after RFN. No correlation was seen between results on MBB and pain relief after RFN. It is still unclear how many medial branch blocks are needed and the criteria for MBB results before proceeding to RFN.

Key words: Facet, medial branch blocks, radiofrequency ablation, chronic low back pain, interventional spine procedures, functional improvement

Pain Physician 2016; 19:163-172 
hronic persistent low back and neck pain occurs in $25 \%$ to $60 \%$ of patients, one year or longer after the initial episode $(1,2)$. It is estimated that $33 \%$ to $65 \%$ of patients with chronic neck pain and $17 \%$ to $44 \%$ of patients with chronic low back pain have facet joint pain (3-10). Facet joints are a common cause of chronic neck and back pain (7-11). Patients with facet joint pain report axial pain, aggravated by movements or activity. Pain is usually referred distally from the affected facet joints. Facet joint pain provocation studies in volunteers and patients demonstrated distinctive pain referral patterns (12-14), however due to significant overlap from adjacent facet joints and other pain generating sources such as the discs, pain arising from facet joints is indistinguishable from other pain generating structures, especially in the thoracic and lumbar spine (15-17). Various clinical tests for facet joint pain have been described (18-21), but none of these can reliably diagnose or distinguish facet joint pain from other sources of pain in the affected region or localize pain to a specific facet joint level $(6,20,22$ 26). A biological marker or surrogate for facet joint pain does not exist. Imaging studies are able to demonstrate with exquisite detail facet joint morphology, but facet joint abnormalities seldom equate with facet joint pain (27-30).

The diagnosis of facet joint pain is established by facet joint block or facet nerve blocks (31-33). The underlying principle for these tests is that local anesthetic block of the affected joint or its nerve supply (medial branch blocks $[\mathrm{MBB}]$ ) will lead to pain relief and painfree movement of the affected joint. A negative test will exclude the joint as source of pain, while a positive test will increase the likelihood that the joint tested is the source of pain (33). Single blocks, however, result in high false positive rates varying from $27 \%$ to $63 \%$ in various studies $(5,8-11,34,35)$. Double controlled local anesthetic blocks are recommended and have a specificity of $88 \%$ and sensitivity of $54 \%$ resulting in few false positive diagnoses, but a high false negative rate. Relaxing the diagnostic criteria to include all patients with reproducible relief, irrespective of duration, increases sensitivity to $100 \%$ but lowers specificity to $65 \%(36,37)$. The prevalence of facet joint pain based on double controlled blocks is estimated to range from $16 \%$ to $44 \%$ in patients with chronic low back pain and $33 \%$ to $65 \%$ in patients with chronic neck pain (4-7,9-11,24).

MBB are also employed to select patients most likely to benefit from radiofrequency neurotomy (RFN), a nerve ablative procedure to treat facet joint pain. Clinical trials that employed dual controlled or placebo controlled MBB to select patients for RFN reported successful outcomes in $60 \%$ to $74 \%$ of patients with chronic neck pain and $53 \%$ to $87 \%$ patients with chronic low back pain (28-41). However, no study determined the correlation between MBB responses and RFN outcomes, specifically whether patients with concordant analgesic responses to dual controlled MBB have superior RFN outcomes as compared to those without concordant analgesic response.

The purpose of this study is to: (1) estimate percentage pain relief, decrease in analgesic use, and increase in activity tolerance after facet joint RFN in patients with chronic neck and back pain; (2) study the correlation between degree and duration of analgesic responses after MBB with RFN treatment outcomes at 3 months follow-up.

\section{Methods}

\section{Study Design}

Retrospective chart review of all patients with chronic neck or low back pain who were treated with facet joint RFN between December 2006 and January 2010. The study was approved by the University Health Sciences IRB Office.

\section{Study Setting}

The study was conducted at a large university hospital in the Midwest in the United States. Patients were recruited from the University Hospital Pain and Spine Clinics.

\section{Data Extraction}

Medical records of patients who were treated with RFN for chronic neck or low back pain were reviewed and the following data were extracted: age, gender, duration of pain, location of pain, clinical and imaging abnormalities, MBB levels and sides, analgesic response to MBB (percentage decrease in pain and duration of pain decrease), RFN level and sides, pain relief and duration of pain relief at regularly scheduled follow-up clinic visits, changes in neck disability index (NDI) and Oswestry Disability Index (ODI), and analgesic use before and after RFN.

\section{Diagnosis of Facet Joint Pain}

A physician with fellowship training and extensive experience performed the MBB (NS) using standard 
technique in an ambulatory surgery center. The target levels for MBB were determined by palpation for paraspinal tenderness and fluoroscopic correlation (18). Spinal needles were placed at target sites, needle position and avascular injection confirmed with contrast, followed by instillation of $0.5 \mathrm{~mL}$ (for cervical MBB) or $1 \mathrm{~mL}$ (for lumbar MBB) of $2 \%$ lidocaine or $0.75 \%$ bupivacaine. MBB were performed at 2 levels for one facet joint. MBB were performed at 3 levels when 2 facet joints were involved on the same side, for instance left L3-L4 medial branch and L5 dorsal ramus blocks were performed for left L4-5 and L5-S1 facet joints. For the C2/3 facet joint, the third occipital nerve was blocked at 3 target points $(31,42)$. A midlevel provider independently evaluated each patient before and after the MBB and obtained pain intensity ratings and checked range of motion. Patients completed an hourly pain rating (in a position that usually provoked pain) for 8 hours and then daily pain ratings for 2 weeks. Pain diaries were reviewed by the treating physician and confirmatory MBB with bupivacaine (MBB2) were scheduled if there was positive analgesic response to the first MBB with lidocaine. According to our routine clinical practice, all patients were informed that 2 different local anesthetic drugs were employed for the first and second MBB, and no information was provided regarding the specific agent used, any expected pain relief, or onset and duration of pain relief after MBB. For this study, positive analgesic response was defined as $70 \%$ or greater pain reduction within 30 minutes of the MBB and lasting from one to 8 hours after the procedure. Percentage pain relief was calculated by the formula ([pre-treatment pain intensity - post treatment pain intensity $\div$ pre-treatment pain intensity] $X 100)$. Those who obtained $70 \%$ or greater reduction in pain with both sets of $\mathrm{MBB}$ (i.e., MBB1 and MBB2) underwent RFN of target nerves $(28,40,43)$.

\section{Treatment of Facet Joint Pain}

RFN was performed at preselected levels by a single physician (NS) with extensive experience in RFN. Insulated 18 gauge radiofrequency probes with 10 $\mathrm{mm}$ exposed tips were placed on target nerves and multiple lesions created at 80 degrees Celsius for 105 seconds (Kimberly-Clark Radiofrequency Generator, Roswell, Ga). In the cervical spine, radiofrequency nerve ablation was performed by both sagittal and oblique approaches $(28,43)$, while in the lumbar spine radiofrequency probes were positioned parallel to the course of the target nerves by an inferiorly declined oblique approach $(40,44,45)$.

\section{Follow Up Visits and Outcome Assessments}

Pain intensity ratings ( 0 to 10 numeric pain rating scale) and NDI (for neck pain) or ODI scores (for low back pain) were collecting before and after RFN. Patients were scheduled for follow-up visits at 4 weeks, $3,6,9$, and 12 months after RFN. Outcomes evaluated at each clinic visit included ODI or NDI, Brief Pain Inventory, pain on $0-10$ numeric pain rating scale and percentage pain relief, change in analgesic medication intake, and patient perception of benefit. The patient perception of benefit was determined by asking patients to provide an estimate of overall percent change in their condition after RFN when compared to their status before RFN. Follow-ups were performed by the treating physician $(\mathrm{SCH})$ or midlevel provider at the spine or pain clinics. Pain diaries were reviewed by a physician, in conjunction with pain diaries from all other procedures, and no RFN follow-ups were scheduled with the provider who performed the MBB and RFN.

\section{Statistical Analysis}

T-tests and Fisher Exact tests were used for categorical data, and Wilcoxon Rank sum tests (MannWhitney U) for non-parametric data. A subgroup analysis was performed, based on analgesic response to MBB in those (a) who obtained $100 \%$ pain reduction and those who obtained $>70 \%$ but $<100 \%$ pain reduction on MBB1 and MBB2, (b) those with 8 hours or less of pain reduction and those with $>8$ hours pain reduction after MBB1 and MBB2. Correlation analysis was performed to determine correlation between (a) percent pain reduction after $\mathrm{MBB} 1$ and $\mathrm{MBB} 2$ and percent pain relief after RFN and (b) duration of pain reduction after MBB1 and MBB2 and percent pain relief after RFN.

\section{Results}

\section{Demographics}

A total of 112 patients with positive analgesic responses to double controlled $\mathrm{MBB}$ were treated with RFN between December 2006 and January 2010. Of the 112 patients, 50 patients had complete data at 3 months follow-up visit and this data was analyzed. Data for the 6 and 12 months visits were incomplete or missing and therefore not included in this analysis.

Table 1 shows the demographic characteristics of this population. The mean (SD) age was 51.2 years (12.4), 56\% were women, mean (SD) body weight 86.5 $\mathrm{kg}$ (23.3), and the median duration of pain was 5 years 
(range 1 - 40 years). Mean baseline pain on $0-10$ numeric pain scale was 5.26 (range $3-8$ ). Twelve patients had coexisting depression ( $24 \%)$ and $3(6 \%)$ had anxiety disorder. Other comorbid medical conditions were migraine headaches, bipolar disorder, spinal cord injury, prostate cancer, hypertension, coronary artery disease, atrial fibrillation, and Parkinson's disease. MRI studies showed degenerative facet disease in 22 patients and degenerative disc disease in 33 patients. Fourteen patients underwent cervical RFN and 36 patients received lumbar RFN. There were 4 patients who required repeat RFN for recurrence of pain after a previously successful RFN (3 lumbar and one cervical).

\section{RFN Outcomes}

Table 2 shows outcomes at 3 months after RFN. Mean pain relief was $47.7 \%$ (33.40) $(P<0.001)$ which was clinically significant and meaningful. Disability

Table 1. Demographics and clinical characteristics of study patients.

\begin{tabular}{|l|l|}
\hline Patient Characteristics & Value $(\mathrm{n}=50)$ \\
\hline Age $(\mathrm{yr})$ & $51.2(12.4)$ \\
\hline Weight $(\mathrm{kg})$ & $86.5(23.3)$ \\
\hline Gender - Female & $28(56 \%)$ \\
\hline Pain Duration $(\mathrm{yr})$ & $5(1-40)$ \\
\hline Psychiatric Disorder & -- \\
\hline Depression & $12(24 \%)$ \\
\hline Anxiety & $3(6 \%)$ \\
\hline RFN Laterality & -- \\
\hline Bilateral & $29(58 \%)$ \\
\hline Right & $15(30 \%)$ \\
\hline Left & $6(12 \%)$ \\
\hline RFN Region & -- \\
\hline Lumbar spine & $36(72 \%)$ \\
\hline Cervical spine & $14(28 \%)$ \\
\hline
\end{tabular}

Reported as mean (SD), median (range), or frequency (\%)
Index represents percentage scores for ODI and NDI. Mean disability score at baseline was $43.1 \%$ (18.0) and at 3 months was $31.0 \%$ (18.3), a statistically significant mean decrease of $12.6(16.6)(P<0.001)$. Disability sub scores for standing and walking improved and approached significance but were not statistically significant. Opioid analgesic consumption decreased in $41 \%$ of patients at the 3 month follow-up, but did not reach statistical significance. Overall, patients perceived $53.2 \%(31.5 \%)$ improvement at 3 months compared to baseline $(P<0.001)$. Unfortunately, due to the small numbers in this study, we were unable to compare cervical and lumbar results.

All 4 patients with repeat RFN, reported pain relief after the repeat RFN; 3 patients experienced greater than $50 \%$ pain relief and one patient reported less than $20 \%$ pain relief. There was $>50 \%$ decrease in disability scores in all 4 patients.

\section{RFN Outcomes and Analgesic Response to MBB1 and MBB2 (Tables 3 and 4):}

Subgroup analysis was performed based on analgesic responses to MBB (MBB1and MBB2): (a) 100\% pain reduction (complete responders) vs. $<100 \%$ pain reduction (partial responders) and (b) $\leq 8$ hours pain reduction (short duration relief) vs. $>8$ hours pain reduction (prolonged relief) after MBB. RFN outcomes (percentage pain relief, disability scores, perceived improvement, and decrease in analgesic use) were compared in these subgroups. (Note 4 patients who had MBB1 were lost to follow-up before MBB2 was performed which accounts for different $\mathrm{N}$ values in Tables 3 and 4).

\section{Complete Responders vs. Partial Responders}

There were no statistically significant differences in pain relief, perceived improvement, and decrease in analgesics use after RFN between complete ( $100 \%$ pain relief) and partial responders ( $<100 \%$ pain relief) (both for MBB1 and MBB2) (Tables 3 and 4). A statistically sig-

Table 2. Decrease in pain, disability index, and analgesic use at 3 month follow-up.

\begin{tabular}{|l|c|c|c|c||}
\hline Measurement & Baseline (n = 50) & 3 Months (n = 38) & Difference $\boldsymbol{P}_{\text {-value }}^{\wedge}$ \\
\hline Disability Index \% & $43.1(18.0)$ & $31.0(18.3)$ & $-12.6(16.6)$ & $<0.001$ \\
\hline Pain relief - \% & -- & $47.7(33.4)$ & -- & $<0.001$ \\
\hline Perceived Improvement - \% & -- & $53.2(31.5)$ & -- & $<0.001$ \\
\hline Analgesic use Reduced & -- & $16(41.0 \%)$ & -- & 0.337 \\
\hline
\end{tabular}

Disability Index = combined ODI and NDI

$\wedge P$-value for ODI is from paired t-test over time, pain drop, and perceived pain drop, $P$-values are from single

t-tests against a null hypothesis value of $25 \%$, and medication reduced $P$-value is from a single proportion test against a null hypothesis of $50 \%$ 
nificant reduction in disability ratings was observed in complete responders (mean $16.2 \pm 17.5, P=0.008$ ) with MBB1 (Table 3) but not with MBB2 (Table 4). Complete responders had significantly higher disability scores at baseline than the partial responders (Table 3$)(P=$ 0.017).

\section{Short Duration Relief Vs. Prolonged Relief}

Short duration relief subgroup after MBB1 $(\leq 8$ hours pain reduction) had significantly higher baseline disability scores than the prolonged relief subgroup (> 8 hours pain reduction). Disability scores remained significantly different between short duration and prolonged pain relief groups at 3 month follow-up of MBB1 (Table 3), however there was no difference between groups in disability scores at 3 months followup post MBB2 (Table 4). There was no statistically significant difference in disability score reduction from baseline between the short duration and prolonged relief subgroups at 3 months follow-up for either MBB1 or MBB2 (Table 3 and 4). Percentage pain relief and patient perceived improvement were statistically better for the prolonged subgroup ( $>8$ hours) as compared to the short duration ( $<8$ hours) relief subgroup after MBB1 (Table 3 ).
There were no statistically significant differences in decrease in analgesic use observed between those with short duration relief $(\leq 8$ hours) and prolonged relief ( $>8$ hours) (Table 3 ) for MBB1. There was no statistically significant difference in any outcome after MBB2 when comparing short versus long duration response (Table 4).

We compared RFN outcomes in 33 patients with concordant responses ( $80 \%$ to $100 \%$ analgesic response after both MBB1 and MBB2) with 11 patients who had discrepant responses (only one of the $2 \mathrm{MBB}$ provided $\geq$ $80 \%$ analgesic response). There were no statistically significant differences in RFN outcomes (decrease in pain and disability scores) between the 2 groups (Table 5).

\section{Correlation of RFN Outcomes with Diagnostic MBB}

Pearson Correlation analysis revealed no significant correlation between percentage pain reduction (analgesic response) after diagnostic MBB and percentage relief in low back pain or neck pain at 3 months after RFN (Fig. 1). Fig. 2 shows a regression model of log of duration of pain relief (hours) with diagnostic MBB and percent decrease in low back pain or neck pain at 3 months after RFN. Neither percentage pain reduction

Table 3. Comparison of MBB 1 analgesic response with RFNneurotomy outcome at 3 months.

\begin{tabular}{|c|c|c|c|c|c|}
\hline RFN Outcomes & MBB Analgesic response & Baseline & 3 Months & Difference & $\mathbf{N}^{\wedge}$ \\
\hline \multirow{4}{*}{$\begin{array}{l}\text { Disability Index (ODI \& } \\
\text { NDI) }\end{array}$} & $100 \%$ Pain reduction & $46.8(17.4)$ & $32.0(18.9)$ & $-16.2(17.5)$ & $34 / 26 / 26$ \\
\hline & $<100 \%$ Pain reduction & $33.7(15.8)^{*}$ & $27.6(18.0)$ & $-3.1(10.5)^{* *}$ & $14 / 11 / 11$ \\
\hline & $>8$ hrs Pain reduction & $32.5(20.2)$ & $16.8(11.4)$ & $-15.4(24.3)$ & $12 / 8 / 8$ \\
\hline & $\leq 8 \mathrm{hrs}$ Pain reduction & $46.5(15.7)^{*}$ & $34.5(18.3)^{\star *}$ & $-11.5(14.4)$ & $36 / 29 / 29$ \\
\hline \multirow{4}{*}{ Pain Relief - \% } & $100 \%$ Pain reduction & -- & $49.7(31.9)$ & -- & 27 \\
\hline & $<100 \%$ Pain reduction & -- & $42.0(40.2)$ & -- & 10 \\
\hline & $>8$ hrs Pain reduction & -- & $73.9(18.6)$ & -- & 8 \\
\hline & $\leq 8$ hrs Pain reduction & -- & $40.4(33.8)^{*}$ & -- & 29 \\
\hline \multirow{4}{*}{ Perceived Improvement - \% } & $100 \%$ Pain reduction & -- & $58.2(29.7)$ & -- & 22 \\
\hline & $<100 \%$ Pain reduction & -- & $40.1(35.7)$ & -- & 9 \\
\hline & $>8$ hrs Pain reduction & -- & $76.7(20.2)$ & -- & 9 \\
\hline & $\leq 8$ hrs Pain reduction & -- & $43.2(31.2)^{*}$ & -- & 22 \\
\hline \multirow{4}{*}{ Decrease in analgesics use } & $100 \%$ Pain reduction & -- & $12(44.4 \%)$ & -- & 27 \\
\hline & $<100 \%$ Pain reduction & -- & $3(27.3 \%)$ & -- & 11 \\
\hline & $>8$ hrs Pain reduction & -- & $4(44.4 \%)$ & -- & 9 \\
\hline & $\leq 8$ hrs Pain reduction & -- & $11(37.9 \%)$ & -- & 29 \\
\hline
\end{tabular}

MBB - Medial Branch Block.

$\wedge$ Sample size at each time point respectively or for 3 months only.

${ }^{*}$ indicates a significant difference between MBB result groups with $P<0.05$.

${ }^{* *}$ indicates a significant difference between MBB result groups with $P<0.01$. 
Pain Physician: March/April 2016: 19:163-172

Table 4. Comparison of MBB 2 analgesic response with RFNneurotomy outcome at 3 months.

\begin{tabular}{|c|c|c|c|c|c|}
\hline RFN Outcomes & MBB Analgesic response & Baseline & 3 Months & Difference & $\mathbf{N}^{\wedge}$ \\
\hline \multirow{4}{*}{ Disability Index (ODI \& NDI) } & $100 \%$ Pain reduction & $40.9(17.2)$ & $25.3(13.1)$ & $-16.3(20.4)$ & $26 / 18 / 18$ \\
\hline & $<100 \%$ Pain reduction & $42.9(15.7)$ & $30.9(15.5)$ & $-10.1(12.1)$ & $18 / 15 / 15$ \\
\hline & $>8$ hrs Pain reduction & $39.7(20.4)$ & $27.2(12.4)$ & $-14.0(22.7)$ & $17 / 12 / 12$ \\
\hline & $\leq 8$ hrs Pain reduction & $43.0(13.7)$ & $28.2(15.5)$ & $-13.1(13.7)$ & $27 / 21 / 21$ \\
\hline \multirow{4}{*}{ Pain Relief - \% } & $100 \%$ Pain reduction & -- & $58.5(33.9)$ & -- & 19 \\
\hline & $<100 \%$ Pain reduction & -- & $41.5(31.2)$ & -- & 14 \\
\hline & $>8$ hrs Pain reduction & -- & $53.8(25.5)$ & -- & 12 \\
\hline & $\leq 8$ hrs Pain reduction & -- & $49.8(37.7)$ & -- & 21 \\
\hline \multirow{4}{*}{ Perceived Improvement - \% } & $100 \%$ Pain reduction & -- & $65.6(29.4)$ & -- & 16 \\
\hline & $<100 \%$ Pain reduction & -- & $42.1(28.2)$ & -- & 12 \\
\hline & $>8$ hrs Pain reduction & -- & $57.5(30.3)$ & -- & 12 \\
\hline & $\leq 8$ hrs Pain reduction & -- & $54.1(32.1)$ & -- & 16 \\
\hline \multirow{4}{*}{ Decrease in analgesic use } & $100 \%$ Pain reduction & -- & $9(47.4 \%)$ & -- & 19 \\
\hline & $<100 \%$ Pain reduction & -- & $5(33.3 \%)$ & -- & 15 \\
\hline & $>8$ hrs Pain reduction & -- & $4(30.8 \%)$ & -- & 13 \\
\hline & $\leq 8$ hrs Pain reduction & -- & $10(47.6 \%)$ & -- & 21 \\
\hline
\end{tabular}

MBB - Medial Branch Block

$\wedge$ Sample size at each time point respectively, or for 3 months only.

* indicates a significant difference between MBB result groups with $P<0.05$.

${ }^{*}$ indicates a significant difference between MBB result groups with $P<0.01$.

Table 5. RFN outcomes in groups with concordant vs. discrepant analgesic responses.

\begin{tabular}{|c|c|c|c||}
\hline \multirow{2}{*}{ RFN Outcomes } & \multicolumn{2}{|c|}{ MBB Response } & \multirow{2}{*}{-value } \\
\cline { 2 - 3 } & $\begin{array}{c}\text { Concordant } \\
(\mathbf{n}=\mathbf{3 3})\end{array}$ & $\begin{array}{c}\text { Discrepant } \\
(\mathbf{n}=\mathbf{1 1})\end{array}$ & \\
\hline Pain relief & $53.1(35.5)$ & $44.4(24.7)$ & 0.469 \\
\hline \multicolumn{4}{|c|}{ Disability scores } \\
\hline Baseline & $39.9(17.6)$ & $47.2(11.4)$ & 0.127 \\
\hline 3 Months & $26.2(13.5)$ & $33.0(16.2)$ & 0.307 \\
\hline Difference & $-12.9(18.5)$ & $-15.1(13.2)$ & 0.715 \\
\hline
\end{tabular}

nor duration of analgesic response after diagnostic MBB correlated with significantly decreased pain at 3 months after RFN.

\section{Discussion}

MBB responses are employed to select patient who might respond to RFN, in that a positive response predicts a good chance of obtaining significant pain relief after percutaneous RFN. There are 2 studies that correlated MBB responses to RFN outcomes $(46,47)$. In Cohen et al's study (47), there were no significant differences in RFN outcomes based on any MBB pain relief cutoff over $50 \%$. Derby et al (46) found that double MBB protocol with a $70 \%$ cut off value for MBB pain relief had better correlation with favorable RFN outcomes as compared with single MBB protocol.

In this retrospective study, we compared percentage pain relief, decrease in disability ratings, and analgesic usage at 3 month follow-up after RFN with percentage pain reduction and duration of analgesia after MBB with lidocaine (MBB1) and bupivacaine (MBB2) and performed a correlation analysis to determine if positive results with either one MBB or both MBB correlated with good outcomes after RFN. We observed that RFN resulted in clinically significant pain relief, improved function as measured on disability scores, and decreased analgesic use at 3 month follow-up, but there was no correlation between percent pain reduction after MBB (either one or both) and pain relief at 3 month follow-up. Similarly no correlation was seen between duration of analgesic effect after MBB (either or both) and pain relief after RFN. These preliminary results suggest that MBB do not predict RFN outcomes. Neither the duration of analgesic response nor the degree of analgesic response (cut off values) predicts pain relief after RFN.

$M B B$ are considered to have both diagnostic and prognostic utility. MBB test if a patients' pain is stemming from a facet joint and establish or exclude the 


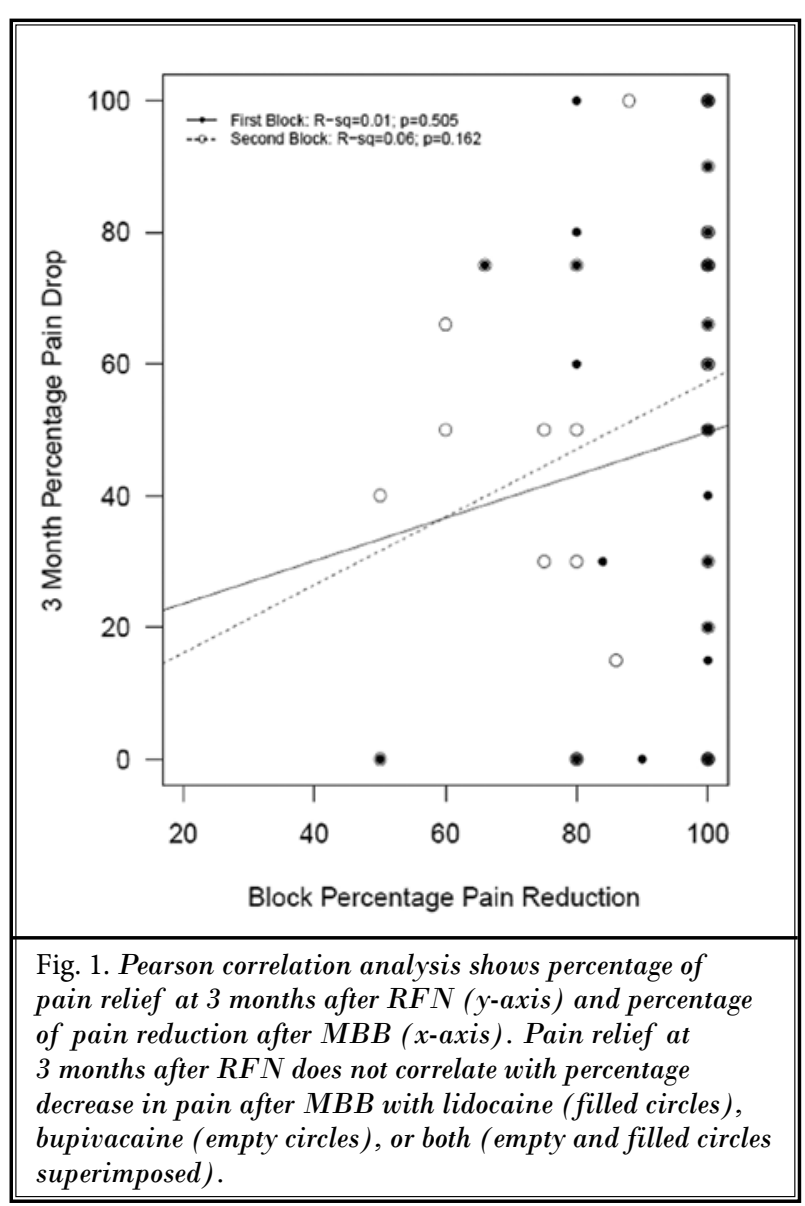

diagnosis of facet joint pain. MBB also enable selection of patients who might respond to RFN. In absence of a reference standard, comparative local anesthetic blocks with lidocaine and bupivacaine are recommended to exclude a false positive response and maximize true positive responses. A positive response is defined as complete relief of pain in the targeted topographical region. Concordant response to controlled MBB, by definition, is long-lasting relief following bupivacaine but short-lasting relief following lidocaine (34). Discordant response is when pain relief following lidocaine is longer than following bupivacaine, but relief in neither instance is within expected duration of action of agent used (34). This diagnostic paradigm, while providing a strategy to treat spinal pain, ignores the complexity of chronic pain. In practice, facet joint pain rarely occurs in isolation and in the majority of patients follows or accompanies disc degenerative changes and secondary alterations in spinal biomechanics. It therefore follows that in patients with chronic spinal pain, there are multiple pain generators; facet joints being one of

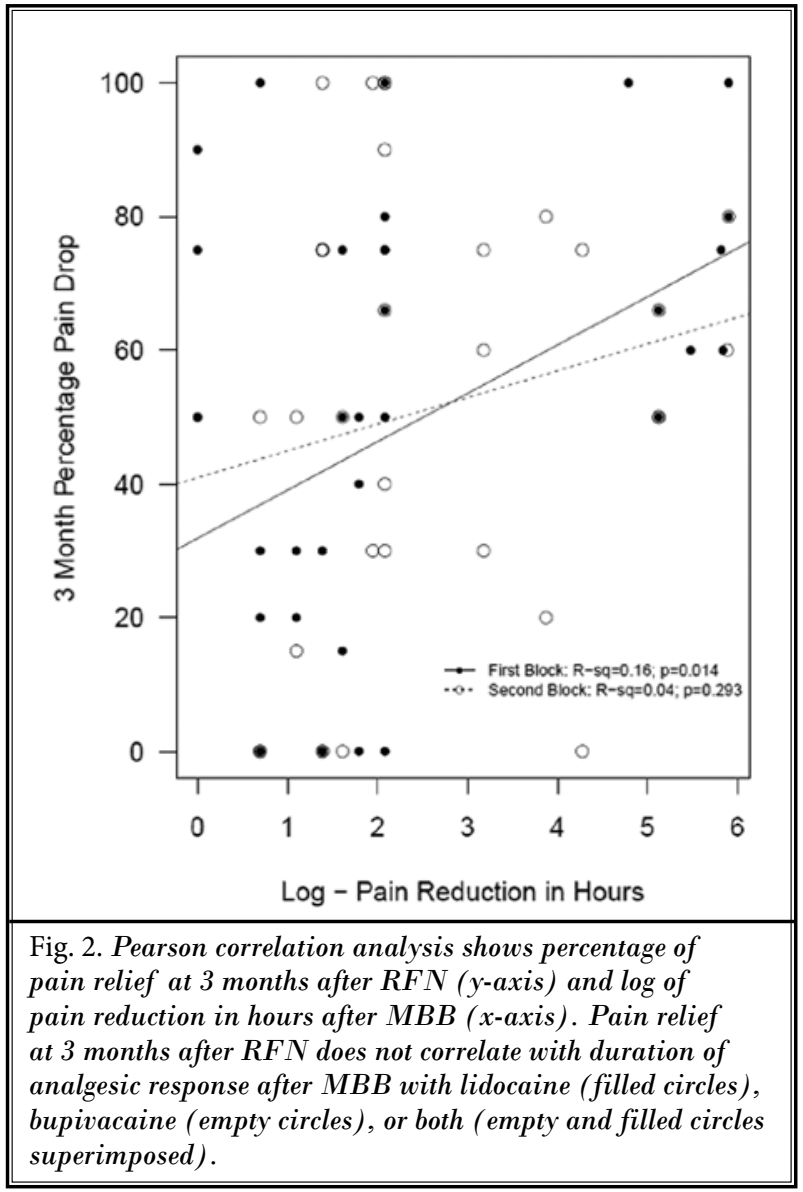

the many pain sources. Hence, complete relief of pain after MBB is inconsistent, unless there is interruption of nociceptive signals from other pain generators in the vicinity. In addition, in patients with chronic pain, such as whiplash injuries, central sensitization occurs and accentuates the overall pain experience (48-50). Complete pain relief $(100 \%$ relief) after MBB is therefore not feasible in these patients, even if it were limited to the area of suggested "affected zone." Pain mapping studies in human volunteers and patients with chronic pain have revealed significant overlap of pain referral zones from adjacent facet joints and other pain generating structures such as the intervertebral discs, thereby limiting the ability of patients to identify or demarcate affected zone (15-17). Furthermore, in patients with central sensitization, a hyperalgesic pain response to sensory stimulation, such as needle insertion, can mask the local anesthetic effect (51-53). Finally, there is variable onset and duration of pain relief after local anesthetic injection, and often prolonged pain relief exceeding the expected duration of local anesthetic ac- 
tion has been observed after diagnostic MBB (54), and was seen in this study also. The mechanisms underlying prolonged pain relief are not well known. Quantitative sensory testing in patients undergoing diagnostic MBB demonstrated altered sensory thresholds and conditioned pain modulation responses that suggest local anesthetic blocks modulate pain by affecting central sensory processing (55). Accordingly, we question the value of applying strict time based criteria to define MBB responses in chronic spinal pain.

While there is agreement that facet joint blocks or MBB are the only reliable method to identify a painful facet joint, there is no consensus on how best to implement the diagnostic protocol and how to select patients for RFN. There is controversy regarding the number of blocks needed prior to RFN: should these be $0,1,2$, or 3 ? Bogduk (56) recommends a placebo control in addition to the dual controlled blocks as the only valid method to establish the diagnosis of lumbar facet joint pain. In contrast to this approach, Cohen et al (57) questions the utility and cost effectiveness of MBB prior to RFN. In a multicenter RCT, patients were randomized to undergo RFN based solely on clinical criteria, or > $50 \%$ pain relief after single or double MBB. Successful outcomes at 3 months follow-up were seen in $22 \%$ with 2 successful MBB, $16 \%$ with one successful MBB, and $33 \%$ without any MBB (57). This study concluded that RFN without a diagnostic block was the most cost effective treatment paradigm (57).

The second controversy relates to what constitutes a positive block. There is no consensus on the ideal cutoff to designate a block as positive. While near complete pain relief ( $>80 \%$ ) after low volume blocks increases true positives, it screens out false negatives and those with multiple pain generators who cannot get a complete analgesic response. Previous studies have found no difference in RF outcomes between cutoff values of $50 \%$ and $80 \%(46,47,58)$. While those with $<50 \%$ cutoff mark after MBB have a poorer outcome after RFN, no difference in outcome based on any MBB pain relief cutoff over $50 \%$ has been observed $(47,58)$. In Cohen et al's study (57), there was no statistically significant difference between percentage pain reduction obtained from single diagnostic blocks among those who had a successful RFN and those who failed RFN.

A limitation of our study is that it is a retrospective uncontrolled study. Despite being retrospective, all data collection was similar to a prospective double blinded study. Other limitations include short follow-up interval of 3 months and small study size due to drop outs/ incomplete data at 6 and 12 months that did not permit analysis of RFN outcomes at long-term follow-up. While a 3 months follow-up is insufficient to determine longterm efficacy of RFN, the purpose of this study was to correlate results of MBB to RFN outcomes and 3 month follow-up data is adequate for this purpose.

This study demonstrated improvement in pain scores and disability indices after RFN similar to previous studies. However, local anesthetic analgesic responses did not correlate with RFN outcomes suggesting that the current diagnostic criteria for selecting patients for RFN based on MBB responses are less than optimal. Prospective multicenter clinical trials are needed to determine optimal selection criteria for facet RFN.

\section{Conclusion}

In this retrospective study patients with facet joint pain diagnosed with comparative controlled MBB underwent RFN and treatment outcomes at 3 months follow-up were correlated with degree and duration of analgesic responses to 2 sets of MBB. Although patients had good pain relief, there was no correlation of outcome with degree or duration of analgesic responses to MBB with either lidocaine or bupivacaine. These results suggest the current diagnostic criteria (concordant analgesic responses) are unreliable in predicting RFN outcomes.

\section{Ackowledgments}

Scott Hetzel, MS, Associate Researcher, Biostatistics and Medical Informatics at UWSMPH for statistical analysis. 


\section{References}

1. Manchikanti L, Singh V, Datta S, Cohen SP, Hirsch JA. Comprehensive review of epidemiology, scope, and impact of spinal pain. Pain Physician 2009; 12: E35-E70.

2. Manchikanti L, Singh V. Review of chronic low back pain of facet joint origin. Pain Physician 2002; 5:83-101.

3. Aprill C, Bogduk N. The prevalence of cervical zygapophyseal joint pain. A first approximation. Spine (Phila Pa 1976) 1992; 17:744-747.

4. Barnsley L, Lord SM, Bogduk N. The prevalence of chronic cervical zygapophysial joint pain after whiplash. Spine (Phila Pa 1976) 1995; 20:20-25; discussion 26

5. Manchikanti L, Singh V, Rivera J, Pampati, $\mathrm{V}$. Prevalence of cervical facet joint pain in chronic neck pain. Pain Physician 2002; 5:243-249.

6. Schwarzer AC, Wang SC, Bogduk N, McNaught PJ, Laurent R. Prevalence and clinical features of lumbar zygapophysial joint pain: A study in an Australian population with chronic low back pain. Ann Rheum Dis 1995; 54:100-106.

7. Lord SM, Barnsley L, Wallis BJ, Bogduk N. Chronic cervical zygapophysial joint pain after whiplash. A placebocontrolled prevalence study. Spine (Phila Pa 1976) 1996; 21:1737-1744; discussion 1744-1745.

8. Manchikanti L, Boswell MV, Singh V, Pampati V, Dammon KS, Beyer CD. Prevalence of facet joint pain in chronic spinal pain of cervical, thoracic, and lumbar regions. BMC Musculoskelet Disord 2004; 5:15.

9. Manchikanti L, Pampati V, Fellow B, Bakhit CE. Prevalence of lumbar facet joint pain in chronic low back pain. Pain Physician 1999; 2:59-64.

10. Sehgal N, Shah RV, McKenzie-Brown $A M$, Everett CR. Diagnostic utility of facet (zygapophysial) joint injections in chronic spinal pain: A systematic review of evidence. Pain Physician 2005; 8: 211-224.

11. Lord SM, Barnsley L, Wallis BJ, Bogduk N. Third occipital nerve headache: A prevalence study. J Neurol Neurosurg Psychiatry 1994; 57:1187-1190.

12. Cooper G, Bailey B, Bogduk N. Cervical zygapophysial joint pain maps. Pain Med 2007; 8:344-353.

13. Dwyer A, Aprill C, Bogduk N. Cervical zygapophyseal joint pain patterns. I: A study in normal volunteers. Spine (Phila
Pa 1976) 1990; 15:453-457.

14. Aprill C, Dwyer A, Bogduk N. Cervical zygapophyseal joint pain patterns. II: A clinical evaluation. Spine (Phila Pa 1976) 1990; 15:458-461.

15. Mooney V, Robertson J. The facet syndrome. Clin Orthop Relat Res 1976;:149-156

16. McCall IW, Park WM, O'Brien JP. Induced pain referral from posterior lumbar elements in normal subjects. Spine (Phila Pa 1976) 1979; 4:441-446.

17. Marks R. Distribution of pain provoked from lumbar facet joints and related structures during diagnostic spinal infiltration. Pain 1989; 39:37-40.

18. Cohen SP, Bajwa ZH, Kraemer JJ, Dragovich A, Williams KA, Stream J, Sireci A, McKnight G, Hurley RW. Factors predicting success and failure for cervical facet radiofrequency denervation: A multicenter analysis. Reg Anesth Pain Med 2007; 32:495-503.

19. Revel ME, Listrat VM, Chevalier XJ, Dougados $M$, N'guyen MP, Vallee $C$, Wybier M, Gires F, Amor B. Facet joint block for low back pain: Identifying predictors of a good response. Arch Phys Med Rehabil 1992; 73:824-828.

20. Revel ME, Poiraudeau S, Auleley GR, Payan C, Denke A, Nguyen M, Chevrot A, Fermanian J. Capacity of the clinical picture to characterize low back pain relieved by facet joint anesthesia. Proposed criteria to identify patients with painful facet joints. Spine (Phila Pa 1976) 1998; 23:1972-1976; discussion 1977.

21. Young S, Aprill C, Laslett M. Correlation of clinical examination characteristics with three sources of chronic low back pain. Spine J 2003; 3:460-465.

22. Jull G, Bogduk N, Marsland A. The accuracy of manual diagnosis for cervical zygapophysial joint pain syndromes. Med J Aust 1988; 148:233-236.

23. King W, Lau P, Lees R, Bogduk N. The validity of manual examination in assessing patients with neck pain. Spine J 2007; 7:22-26.

24. Schwarzer AC, Aprill CN, Derby R, Fortin J, Kine G, Bogduk N. Clinical features of patients with pain stemming from the lumbar zygapophysial joints. Is the lumbar facet syndrome a clinical entity? Spine (Phila Pa 1976) 1994; 19:1132-1137.

25. Schwarzer AC, Derby R, Aprill CN, Fortin J, Kine G, Bogduk N. Pain from the lumbar zygapophysial joints: A test of two models. J Spinal Disord 1994; 7:331-336.
26. Laslett M, Oberg B, Aprill CN, Mcdonald B. Zygapophysial joint blocks in chronic low back pain: A test of Revel's model as a screening test. BMC Musculoskelet Disord 2004; 5:43.

27. Schwarzer AC, Wang, SC, O’Driscoll D, Harrington T, Bogduk N, Laurent R. The ability of computed tomography to identify a painful zygapophysial joint in patients with chronic low back pain. Spine (Phila Pa 1976) 1995; 20:907-912.

28. Makki D, Khazim R, Zaidan AA, Ravi K, Toma T. Single photon emission computerized tomography (SPECT) scanpositive facet joints and other spinal structures in a hospital-wide population with spinal pain. Spine ] 2010; 10:58-62.

29. Kalichman L, Li L, Kim DH, Guermazi A, Berkin V, O'Donnell CJ, Hoffmann U, Cole R, Hunter DJ. Facet joint osteoarthritis and low back pain in the community-based population. Spine (Phila Pa 1976) 2008; 33:2560-2565.

30. Stojanovic MP, Sethee J, Mohiuddin M, Cheng J, Barker A, Wang J, Palmer W, Huang A, Cohen SP. MRI analysis of the lumbar spine: $C a n$ it predict response to diagnostic and therapeutic facet procedures? Clin J Pain 2010; 26:110-115.

31. Barnsley L, Bogduk N. Medial branch blocks are specific for the diagnosis of cervical zygapophyseal joint pain. Reg Anesth 1993; 18:343-350.

32. Barnsley L, Lord S, Bogduk N. Comparative local anaesthetic blocks in the diagnosis of cervical zygapophysial joint pain. Pain 1993; 55:99-106.

33. Kaplan M, Dreyfuss P, Halbrook B, Bogduk N. The ability of lumbar medial branch blocks to anesthetize the zygapophysial joint. A physiologic challenge. Spine (Phila Pa 1976) 1998; 23:1847-1852.

34. Barnsley L, Lord S, Wallis B, Bogduk $\mathrm{N}$. False-positive rates of cervical zygapophysial joint blocks. Clin J Pain 1993; 9:124-130.

35. Schwarzer AC, Aprill CN, Derby R, Fortin J, Kine G, Bogduk N. The false-positive rate of uncontrolled diagnostic blocks of the lumbar zygapophysial joints. Pain 1994; 58:195-200.

36. Bogduk N. International Spinal Injection Society guidelines for the performance of spinal injection procedures. Part 1: Zygapophysial joint blocks. Clin J Pain 1997; 13:285-302.

37. Lord SM, Barnsley L, Bogduk N. The utility of comparative local anesthet- 
ic blocks versus placebo-controlled blocks for the diagnosis of cervical zygapophysial joint pain. Clin J Pain 1995; 11:208-213.

38. Lord SM, Barnsley L, Bogduk N. Percutaneous radio-frequency neurotomy for chronic cervical zygapophyseal-joint pain. N Engl J Med 1996; 335:1721-1726.

39. MacVicar J, Borowczyk JM, MacVicar AM, Loughnan BM, Bogduk N. Cervical medial branch radiofrequency neurotomy in New Zealand. Pain Med 2012; 13:647-654.

40. Dreyfuss P, Halbrook B, Pauza K, Joshi A, McLarty J, Bogduk N. Efficacy and validity of radiofrequency neurotomy for chronic lumbar zygapophysial joint pain. Spine (Phila Pa 1976) 2000; 25:1270-1277.

41. McDonald, GJ, Lord SM, Bogduk N. Long-term follow-up of patients treated with cervical radiofrequency neurotomy for chronic neck pain. Neurosurgery 1999; 45:61-67; discussion 67-68.

42. Bogduk N, Marsland A. The cervical zygapophysial joints as a source of neck pain. Spine (Phila Pa 1976) 1988; 13:610-617.

43. Govind J, King W, Bailey B, Bogduk $N$. Radiofrequency neurotomy for the treatment of third occipital headache. J Neurol Neurosurg Psychiatry 2003; 74:88-93.

44. Lau P, Mercer S, Govind J, Bogduk N. The surgical anatomy of lumbar medial branch neurotomy (facet denervation). Pain Med 2004; 5:289-298.

45. Bogduk N, Long DM. Percutaneous lumbar medial branch neurotomy: A modification of facet denervation. Spine (Phila Pa 1976) 1980; 5:193-200.

46. Derby R, Melnik I, Lee JE, Lee SH. Correlation of lumbar medial branch neurotomy results with diagnostic medial branch block cutoff values to optimize therapeutic outcome. Pain Med 2012; 13:1533-1546.

47. Cohen SP, Strassels SA, Kurihara C, Griffith SR, Goff B, Guthmiller K, Hoang HT, Morlando B, Nguyen C. Establishing an optimal "cutoff" threshold for diagnostic lumbar facet blocks: A prospective correlational study. Clin J Pain 2013; 29:382-391.

48. Van Oosterwijck J. Evidence for central sensitization in chronic whiplash: A systematic literature review. Eur J Pain 2013; 17:299-312.

49. Sterling M. Differential development of sensory hypersensitivity and a measure of spinal cord hyperexcitability following whiplash injury. Pain 2010; 150: 501-506.

50. Banic B, Petersen-Felix S, Andersen OK, Radanov BP, Villiger PM, ArendtNielsen L, Curatolo M. Evidence for spinal cord hypersensitivity in chronic pain after whiplash injury and in fibromyalgia. Pain 2004; 107:7-15.

51. Lemming D, Graven-Nielsen T, Sörensen J, Arendt-Nielsen L, Gerdle B. Widespread pain hypersensitivity and facilitated temporal summation of deep tissue pain in whiplash associated disorder: An explorative study of women. J Rehabil Med 2012; 44:648-657.

52. Koelbaek Johansen M, Graven-Nielsen T, Schu Olesen A, Arendt-Nielsen.
Generalised muscular hyperalgesia in chronic whiplash syndrome. Pain 1999; 83:229-234.

53. Curatolo M, Petersen-Felix S, ArendtNielsen L, Giani C, Zbinden AM, Radanov BP. Central hypersensitivity in chronic pain after whiplash injury. Clin J Pain 2001; 17:306-315.

54. Derby R, Melnik I, Choi J, Lee J. Indications for repeat diagnostic medial branch nerve blocks following a failed first medial branch nerve block. Pain Physician 2013; 16:479-488.

55. Chua NH, Vissers KC, Arendt-Nielsen L, Wilder-Smith $\mathrm{OH}$. Do diagnostic blocks have beneficial effects on pain processing? Reg Anesth Pain Med 2011; 36: 317-321.

56. Bogduk N. On diagnostic blocks for lumbar zygapophysial joint pain. F1000 Med Rep 2010; 2:57.

57. Cohen SP, Williams KA, Kurihara C, Nguyen C, Shields C, Kim P, Griffith SR, Larkin TM, Crooks M, Williams N, Morlando B, Strassels SA. Multicenter, randomized, comparative cost-effectiveness study comparing 0,1 , and 2 diagnostic medial branch (facet joint nerve) block treatment paradigms before lumbar facet radiofrequency denervation. Anesthesiology 2010; 113: 395-405.

58. Cohen SP, Stojanovic MP, Crooks M, Kim P, Schmidt RK, Shields $\mathrm{CH}$, Croll S, Hurley RW. Lumbar zygapophysial (facet) joint radiofrequency denervation success as a function of pain relief during diagnostic medial branch blocks: A multicenter analysis. Spine J 2008; 8: 498-504. 